\title{
Penerapan mesin penyerut bambu pada pengrajin bambu irat sebagai upaya peningkatkan kualitas serutan bambu
}

\author{
Ika Yuniwati ${ }^{1 *}$, Anggra Fiveriati ${ }^{2}$, Ninik Sri Rahayu ${ }^{3}$, Muhammad Rizki \\ Azizi $^{4}$, Moh Nur Afandi ${ }^{5}$
}

${ }^{1}$ Politeknik Negeri Banyuwangi, Indonesia, email: ika@poliwangi.ac.id

${ }^{2}$ Politeknik Negeri Banyuwangi, Indonesia, email: anggrafiveriati@poliwangi.ac.id

${ }^{3}$ Politeknik Negeri Banyuwangi, Indonesia, email: ninikrahayu@poliwangi.ac.id

${ }^{4}$ Politeknik Negeri Banyuwangi, Indonesia, email: azizirizki97@gmail.com

5Politeknik Negeri Banyuwangi, Indonesia, email: mohnurafandi78@gmail.com

${ }^{*}$ Koresponden penulis

\section{Info Artikel}

Diajukan: 26 Agst 2020

Diterima: 24 Des 2020

Diterbitkan: 02 Jan 2021

Keywords:

bamboo; shrink machine; quality of bamboo slice

Kata Kunci:

bambu; mesin penyerut; kualitas iratan bambu

Lisensi:

cc-by-sa

\begin{abstract}
Bamboo is a very easy plant found in Indonesia. This plant is very easy to grow and develops into many especially in tropical climates, so the bamboo is mostly grown on the river banks. Bamboo utilization is one form of an abundance of bamboo influences. Bamboo is widely used for the needs of making household and various kinds of crafts as well as wicker. This webbing is sold as a source for the makers' income. Gintangan is a village located in Banyuwangi whose majority of people have the expertise of making wicker. Manufacture of webbing that requires thin bamboo sheets as raw material woven. Development of a bamboo ambush machine is needed to assist the partner in Gintangan Village as a tool to accelerate the process of making bamboo slices thin so that the manufacturing process becomes faster at the partner in Sanggar Kerajinan Bambu Karya Nyata. This bamboo-absorbing tool was developed to accelerate the process without having to do manual bamboo watering which is very time-consuming. The presence of these machines can increase the production of webbing rapidly and can increase the profit of partners because it reduces the cost for employees of the bamboo shredder.
\end{abstract}

Abstrak
Bambu merupakan tumbuhan yang sangat mudah dijumpai di
Indonesia. Tumbuhan ini sangat mudah tumbuh dan berkembang
sangat banyak terutama di daerah beriklim tropis, sehingga bambu ini
kebanyakan tumbuh di bantaran sungai. Pemanfaatan dari bambu
merupakan salah satu bentuk pengaruh melimpahnya bambu. Bambu
ini banyak dimanfaatkan untuk kebutuhan membuat mesin rumah
tangga dan berbagai macam kerajinan seperti halnya anyaman.
Anyaman dijual sebagai sumber penghasilan bagi pembuatnya.
Gintangan merupakan sebuah desa yang terletak di banyuwangi yang
masyarakatnya mayoritas memiliki keahlian membuat anyaman.
Pembuatan anyaman membutuhkan lembaran bambu tipis sebagai
bahan baku anyaman. Pengembangan mesin penyerut bambu
diperlukan untuk membantu mitra yang ada di desa Gintangan untuk
mempercepat proses pembuatan iratan bambu yang tipis agar proses
pembuatannya menjadi lebih cepat di tempat mitra yaitu Sanggar
Kerajinan Bambu Karya Nyata. Mesin penyerut bambu ini
dikembangkan untuk mempercepat proses tanpa harus melakukan
pengiratan bambu secara manual yang sangat memakan waktu.


Adanya mesin ini dapat meningkatkan produksi anyaman dengan cepat dan dapat meningkatkan keuntungan mitra karena mengurangi biaya untuk karyawan bagian penyerut bambu.

\section{PENDAHULUAN}

Masyarakat Indonesia telah lama mengenal Bambu. Masyarakat memanfaatkan Bambu sebagai produk bambu yang memiliki hubungan dengan proses perkembangan budaya yang ada di Indonesia. Bambu memiliki peranan yang cukup penting, baik Bambu tumbuh secara alami maupun Bambu hasil budidaya. Bambu digunakan sebagai substitusi kayu pada beberapa keperluan. Hal tersebut dikarenakan Bambu merupakan bahan berlignoselulosa. Bambu mempunyai daur tebang yang lebih pendek dibandingkan kayu. Adapun tujuan penggunaan bambu antara lain batangnya mudah dipanen serta dikerjakan untuk berbagai keperluan. Tujuan itu diantaranya mulai dari bahan pangan pada bagian rebungnya yang dapat dimakan. Selain itu rebungnya juga dapat dibuat mesin rumah tangga, bahan pembuat kertas, kerajinan-kerajinan, hingga mebel. Selain itu dapat juga sebagai konstruksi pemukiman serta kebutuhan konsumen lainnya (Sumpena \& Jemadi, 2017; Suryanto et al., 2015).

Pada daerah tropis diantaranya benua Asia, Benua Afrika dan Benua Amerika, Bambu tumbuh dengan sangat baik. Benua Asia Merupakan daerah penyebaran bambu terbesar (Sary et al., 2018; Triplett et al., 2010). Tanaman bambu yang dikenal pada umumnya berbentuk rumpun-rumpun. Bambu tersebut memiliki arah pertumbuhan yang tegak, kadang-kadang memanjat pula, serta batangnya juga mengayu. Batang bambu ujungnya agak menjuntai, apabila Bambu sudah mulai tinggi dan daun-daunya seakan melambai-lambai, Tinggi tanaman bambu secara umum yaitu sekitar 0,3 m sampai $30 \mathrm{~m}$. Bambu memiliki diameter batangnya $0,25-25 \mathrm{~cm}$ dan ketebalan dindingnya sampai $25 \mathrm{~mm}$ Tanaman bambu dapat mencapai umur yang panjang dan biasanya mati tanpa berbunga (Muhtar et al., 2017; Riastuti et al., 2019).

Secara Biofisik, pohon bambu menghasilkan selulosa per ha 2-6 kali lebih besar dari kayu pohon pinus. Peningkatan biomassa bambu per hari 10$30 \%$ dibanding 2,55 untuk pohon kayu pinus. Bambu dapat dipanen dalam 4 tahun, lebih singkat dibanding 8-20 tahun untuk jenis pohon kayu pinus. Di daerah jawa disebut dengan pring. Adapun secara internasional bambu dikenal dengan sebutan bamboo. Di Indonesia Bambu kurang lebih memiliki 125 jenis bambu, sebagian ada yang tumbuh liar serta belum digunakan secara maksimal. Bambu betung merupakan salah satu jenis bambu yang banyak tumbuh di wilayah Indonesia (Arsad, 2015; Clark et al., 2015; Malau et al., 2009).

Gintangan merupakan salah satu Desa yang berada di daerah Kabupaten Banyuwangi, wilayah tersebut terkenal sebagai tempat para pengerajin bambu yang menggunakan keahlian secara turun temurun oleh setiap keluarga masing-masing. Pengerajin bambu di wilayah tersebut melakukan keahliannya masih dengan menggunakan teknik secara manual 
(hand made) mulai proses awal hingga akhir. Bambu yang digunakan, bukanlah sembarang bambu yaitu hanya bambu tutul dan bambu apus saja.

Bambu apus memiliki warna batang hijau ketika masih segar dan setelah kering berwarna krem. Masing-masing rumpun terdapat sekitar 33 sampai 68 batang, per 5 batang Bambu hanya terdapat sekitar 1-2 rumpun bamboo. Semua pada umumnya tumbuh di tepian sungai. Panjang batang memiliki kisaran antara 11-14 meter, memiliki jumlah ruas sekitar 29 ruas; panjang ruas di bagian pangkal $26-32 \mathrm{~cm}$, kemudian bagian tengah $48-50 \mathrm{~cm}$, serta bagian ujung 37-44 cm. Panjang diameter batang di bagian pangkal dan tengah kurang lebih $7,5 \mathrm{~cm}$, serta bagian ujung $6,1 \mathrm{~cm}$. Sementara itu, Bambu memiliki ketebalan batang di bagian pangkal $0,84 \mathrm{~cm}$, tengah $0,68 \mathrm{~cm}$ dan ujung $0,52 \mathrm{~cm}$. Bambu ini hidup pada $\mathrm{pH}$ tanah 6,2 dengan suhu $29,8^{\circ}$ serta kelembaban 69\% (kadar air). Adapun kebermanfaatan bambu apus diantaranya Bambu ini dapat digunakan sebagai bahan anyaman, tampah, tali temali, mesin rumah tangga, konstruksi ringan, dan kandang burung. Bambu apus juga memiliki kualitas serat, baik untuk bahan baku pulp dan kertas (Hadi et al., 2017; Riastuti et al., 2019).

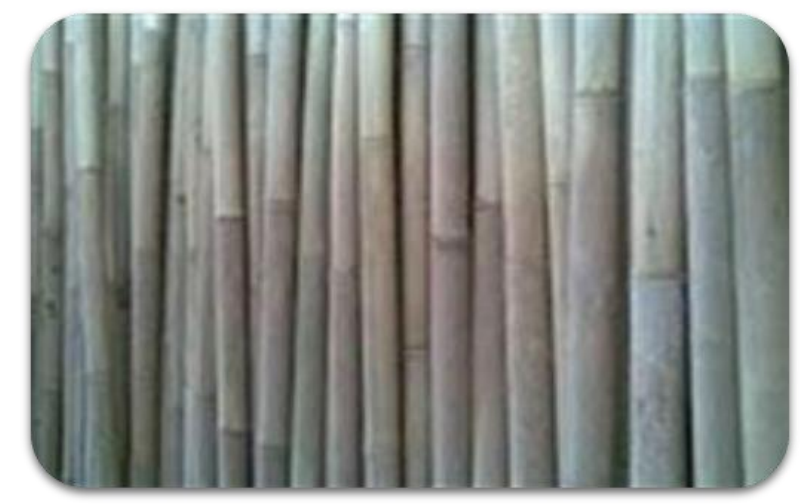

Gambar 1. Bambu Apus di Tempat Mitra

Bentuk bambu tutul pada satu rumpun terdapat sekitar 14 batang. Bambu memiliki panjang lebih dari 13 meter, panjang diameter antara 8 sampai $9 \mathrm{~cm}$, dan sekitar 20 ruas. Berat jenis Bambu tutul antara 0,40-0,62. Pada bagian pangkal bambu tutul terdapat rata-rata retensi bahan pengawet boron $28,85 \mathrm{~kg} / \mathrm{m} 3$, kemudian di bagian tengah $32,38 \mathrm{~kg} / \mathrm{m} 3$, dan bagian ujung $33,92 \mathrm{~kg} / \mathrm{m} 3$. Adapun retensi tertinggi juga terdapat pada bagian ujung bambu, Sedangkan retensi terendah terdapat pada bagian pangkal. Hal ini menunjukan bahwa bagian pangkai tengah dan ujung tidak lebih permeable dibandingkan dengan di bagian ujung bambu tutul. Hal itu memberikan makna, bambu tutul mempunyai sifat keterawetan tingkat 1 atau sangat mudah di awetkan. Adapun hasil dari uji ketahanan terhadap rayap tanah (coptotermes curvignatus), berdasarkan pada jumlah rayap yang hidup (natalitas) menunjukkan bahwa bambu tutul lebih disenangi rayap tanah (Jasni et al., 2017). 


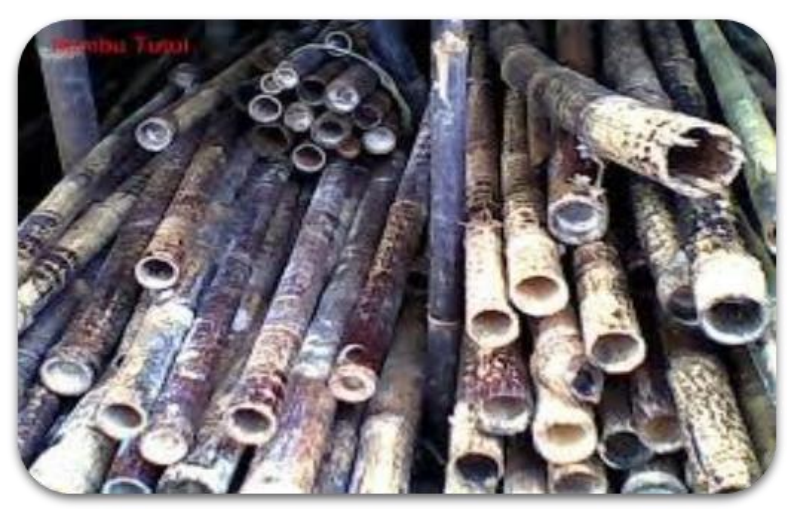

Gambar 2. Bambu Tutul di Tempat Mitra

Mitra dalam pengabdian ini yaitu Sanggar Kerajinan Bambu Karya Nyata. Sanggar tersebut merupakan salah satu pengrajin bambu irat di Desa Gintangan yang memiliki kurang lebih 5-10 karyawan dalam proses produksinya. Kerajinan yang dibuat yaitu kerajinan anyaman bambu. Kerajinan yang diproduksi di Desa Gintangan ini sudah dipasarkan secara nasional dan internasional. Pada proses produksi anyaman tersebut dilakukan proses penyerutan bambu. Penyerutan merupakan melicinkan atau mengubah bentuk benda yang tidak beraturan menjadi beraturan, mesin penyerut batang bambu manual saat ini masih banyak digunakan oleh pengerajin rumahan atau home industry. Adapun keterbatasan mesin penyerut ini, para pengerajin dituntut untuk memenuhi kebutuhan pasar terhadap kerajinan bambu, tetapi pengerajin tidak bisa berbuat lebih kecuali hanya dengan tekun dan rajin dalam proses memproduksi bahan baku kerajinan bambu (tirai) dengan menggunakan cara manual (Winarno \& Rusdiyantoro, 2016).

Kondisi ekonomi Sanggar Kerajinan Bambu Karya Nyata masih belum menjangkau harga mesin penyerut dalam proses penyerutan bambunya. Oleh karena itu pengusul akan mengembangkan mesin penyerut bambu sesuai dengan kebutuhan Sanggar Kerajinan Bambu Karya Nyata. Setelah sosialisasi penggunaan dan perawatan mesin penyerut bambu dilakukan kemudian mesin diberikan kepada Sanggar Bambu Karya Nyata agar dapat meningkatkan hasil produksinya secara berkelanjutan.

\section{METODE PELAKSANAAN}

Adapun proses pengembangan mesin penyerut bambu ini melalui beberapa tahapan yaitu survei kondisi bambu di tempat mitra kemudian melakukan pengembangan mesin penyerut bambu, melakukan uji hasil penyerutan bambu di tempat mitra, melakukan sosialisasi penggunaan dan perawatan mesin penyerut bambu. Tahap selanjutnya setelah sosialisasi dilakukan serah terima mesin penyerut bambu.

Tahapan yang pertama survei kondisi bambu di tempat mitra. Hasil dari survei pertama yang dilakukan tim pengusul bambu yang digunakan 
ditempat mitra yaitu bambu apus dan bambu tutul. Oleh karena itu mesin penyerut bambu yang dikembangkan nantinya harus dapat melakukan penyerutan kedua jenis bambu tersebut. Survei kedua dilakukan untuk menentukan kualitas serutan yang lebih baik dari serutan secara manual. Ini dilakukan untuk mempertimbangkan desain mesin penyerut bambu yang akan dikembangkan agar sesuai dengan kondisi mitra.

Tahap kedua yaitu pengembangan Mesin Penyerut Bambu. Kegiatan pada tahap ini yaitu membentuk skema pemodelan dan desain mesin secara keseluruhan yang digunakan untuk mengetahui posisi komponen-komponen, ukuran, dan bentuk mesin yang akan memudahkan dalam proses pembuatan produk sehingga tidak menyimpang dari rencana awal (Rofii et al., 2018). Desain tersebut sudah terdapat pada lampiran Kemudian dilakukan persiapan mesin dan bahan yang akan digunakan yaitu meliputi bahan-bahan utama serta perangkat/komponen yang akan digunakan untuk membentuk mesin yang akan dibuat. Pemilihan komponen ditinjau dari segi harga dan kualitas barang yang digunakan menyesuaikan alokasi dana yang tersedia. Setelah melakukan pendesainan dan persiapan mesin/bahan, langkah selanjutnya membuat mesin tersebut sesuai dengan yang telah direncanakan sebelumnya.

Selanjutnya pada tahap ketiga meliputi kegiatan sosialisasi penggunaan dan perawatan mesin. Tahap Sosialisasi dilakukan agar para karyawan yang bekerja di Sanggar Kerajinan Bambu Karya Nyata dapat mengoperasikan mesin dengan baik. Selain itu juga karyawan dapat melakukan perawatan mesin penyerut bambu dengan baik. Kegiatan ini dilakukan di tempat mitra. Adapun kontribusi mitra pada kegiatan ini yaitu Mitra bersama pengusul menentukan kualitas serutan yang diinginkan kemudian dilakukan uji coba. Dalam hal ini mitra menyediakan bambu uji coba mesin. Kemudian setelah mesin selesai dikembangkan dilakukan sosialisasi kepada karyawan. Kontribusi lain dari mitra yaitu melakukan persiapan sosialisasi diantaranya tempat sosialisasi dan perlengkapan saat sosialisasi.

Langkah evaluasi pelaksanaan dan keberlanjutan program meliputi kegiatan monitoring dan evaluasi untuk melihat sejauh mana keberhasilan dari pelaksanaan program pengabdian masyarakat. Serta bertujuan untuk mengetahui apakah ditemukan masalah atau kendala yang mempersulit sehingga program ini dapat berjalan dengan lancar dan bermanfaat untuk Sanggar Kerajinan Bambu Karya Nyata.

Langkah evaluasi pelaksanaan program diukur pada beberapa kegiatan diantaranya koordinasi kegiatan selama di tempat mitra, proses pengembangan mesin penyerut bambu, sosialisasi penggunaan dan perawatan mesin, pelaporan kegiatan pada pihak pemberi Dana. Tahap awal setelah dilakukan survei lokasi dan koordinasi kegiatan dengan mitra serta identifikasi permasalahan dan solusi permasalahan. Kegiatan tersebut dievaluasi melalui penentuan permasalahan yang spesifik dan solusi dari permasalahan mitra serta penentuan waktu sosialisasi. Langkah berikutnya melakukan proses pengembangan mesin penyerut bambu (Kristanto \& Arifin, 2012). Kegiatan tersebut dievaluasi melalui adanya mesin penyerut bambu 
yang sesuai dengan kondisi kegiatan produksi dari mitra. Langkah ketiga sosialisasi mesin penyerut bambu dilakukan kepada karyawan yang bekerja di Sanggar Kerajinan Karya Nyata yang dievaluasi dengan adanya pelaksanaan sosialisasi sesuai dengan waktu yang ditentukan dan adanya karyawan yang mencoba melakukan penyerutan bambu. Langkah berikutnya yaitu pelaporan kemajuan kegiatan dan laporan akhir kegiatan. Kegiatan itu dievaluasi dengan pengumpulan laporan kemajuan ke P3M Politeknik Negeri Banyuwangi. Setelah dilakukan proses publikasi baik itu jurnal maupun media massa diharapkan dengan adanya program pengabdian masyarakat ini nantinya dapat dijadikan referensi untuk pengembangan mesin-mesin terkait produksi Home Industry yang sudah ada di masyarakat agar kegiatan Home Industry khususnya di Banyuwangi meningkatkan pendapatan masyarakat.

Setelah program pengabdian masyarakat ini berakhir, diharapkan adanya keberlanjutan dari program ini diantaranya Mitra mampu meningkatkan hasil produksinya dengan menggunakan mesin yang telah dikembangkan secara baik dan mandiri serta dapat melakukan perawatannya; para pekerja di Sanggar Kerajinan Karya Nyata dapat melakukan proses penyerutan lebih baik dari sebelumnya dan lebih aman; dan adanya inovasi baru yang ditujukan kepada pengrajin bambu irat di Desa Gintangan Kecamatan Blimbingsari untuk terus melakukan produksi anyaman yang lebih baik lagi.

\section{HASIL DAN PEMBAHASAN}

Pembuatan mesin penyerut bambu diarahkan untuk membantu mitra dalam pembuatan bahan dasar dari anyaman bambu yaitu bentuk iratan bambu tipis dari proses manual menjadi proses yang lebih cepat serta efisien.

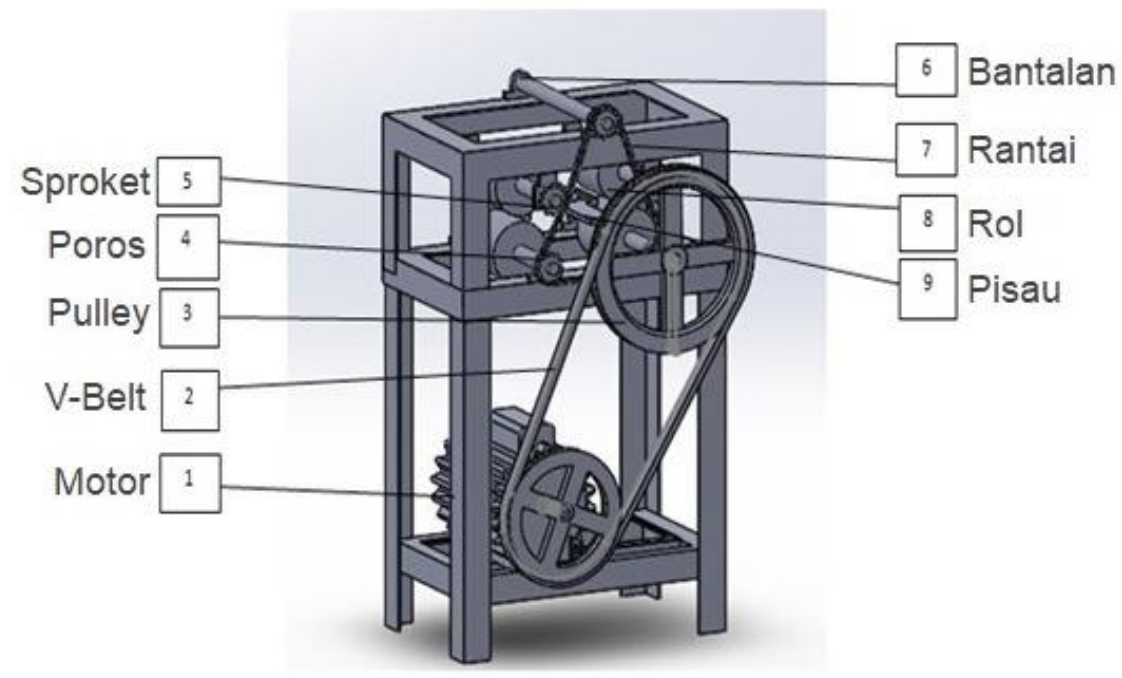

Gambar 3. Desain Mesin Penyerut Bambu 
Mesin penyerut bambu ini didesain menggunakan software solid work (Ibrahim et al., 2019) dengan desain dan bentuk seminimalis mungkin agar dapat dipindahkan oleh perorangan serta tidak banyak memakan tempat untuk menyimpannya. Proses pembuatan mesin ini memakan waktu sekitar 2 bulan lebih beserta proses penyelesaian dan penyempurnaan kinerja mesin sebelum di serahkan kepada mitra. Sebelum dilakukan penyerahan, dilakukan uji coba mesin 1 bulan sebelum penyerahan. Proses uji coba dapat dilihat pada Gambar 4.

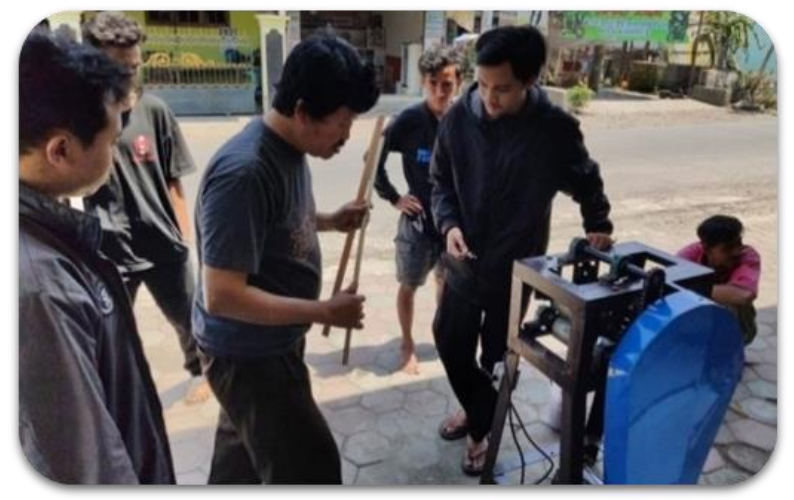

Gambar 4. Proses Percobaan Penyerutan Bambu

Proses ini dilakukan untuk mengetahui bentuk dan hasil dari penyerutan bambu oleh mesin dengan kriteria ketebalan bambu yang disesuaikan dengan kebutuhan anyaman nantinya yaitu dengan tebal antara $0,5 \mathrm{~mm}$ sampai dengan 1,2 $\mathrm{mm}$ dan lebar maksimal untuk anyaman yaitu 2,5 $\mathrm{cm}$ maksimal.

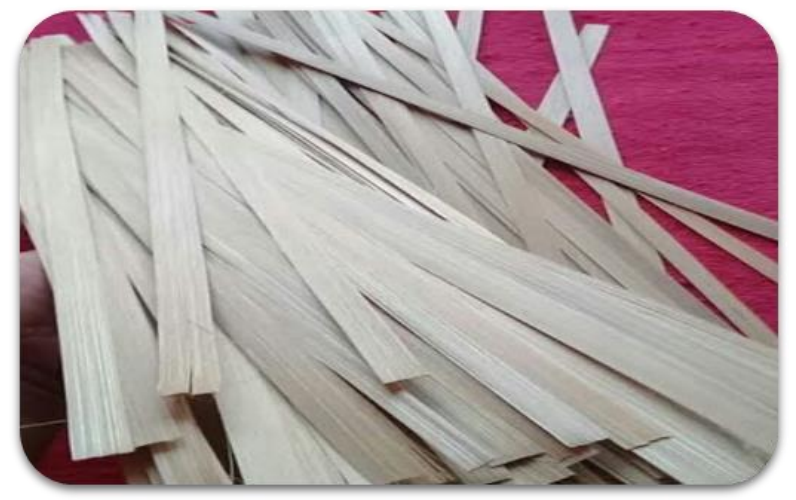

Gambar 5. Hasil Serutan Bambu

Hasil penyerutan bambu ini membuahkan hasil berupa lembaran bambu tipis yang digunakan untuk anyaman. Dengan tebal antara 0,8-1 mm dan lebar dari bambu sebesar $1 \mathrm{~cm}$. Untuk ketebalan bambu yang di inginkan bisa dirubah sesuai dengan kebutuhan pengrajin dengan menaikkan dudukan 
pisau untuk hasil tebal dan menurunkan dudukannya untuk hasil yang lebih tipis lagi. Proses pembuatan mesin penyerut bambu dilakukan di kampus Politeknik Negeri Banyuwangi dengan memanfaatkan lab permesinan di Prodi Teknik Mesin. Proses pembuatannya dilaksanakan pada bulan Juni sampai bulan Agustus. Kemudian proses selanjutnya yaitu proses sosialisai terhadap mitra yang ada pada Sanggar Kerjinan Bambu Karya Nyata di Desa Gintangan pada tanggal 14 September 2019 seperti pada gambar 6. Proses Sosialisasi di Tempat Mitra dihadiri pelaksana pengabdian, mahasiswa, pemilik sanggar, dan pekerja di Sanggar Bambu Karya Nyata.

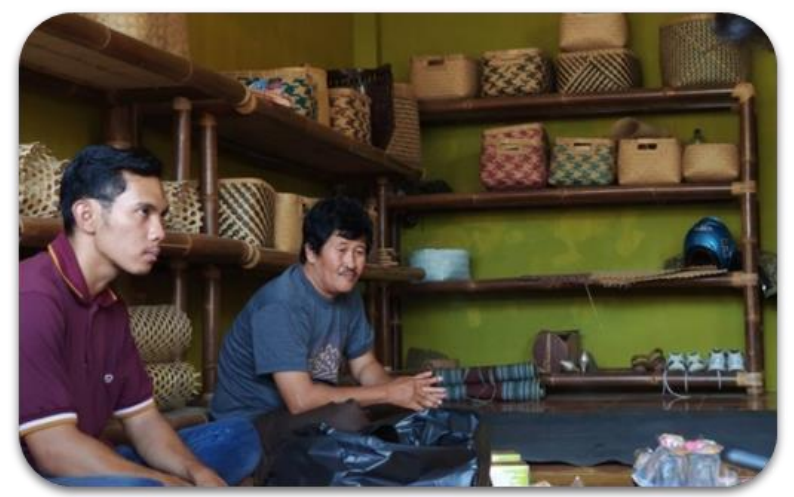

Gambar 6. Proses Sosialisasi di Tempat Mitra

Sosialisasi tentang proses kerja dan perawatan terhadap mesin penyerut bambu ini bertujuan memberikan bentuk pengarahan terhadap proses kerja mesin, cara menggunakan dan bentuk perawatan yang perlu diketahui. Adanya pengarahan ini nantinya mitra bisa melakukan proses perawatan secara rutin agar mesin dapat dipakai jangka panjang dan mengurangi kegagalan produk saat proses penyerutan bambu.

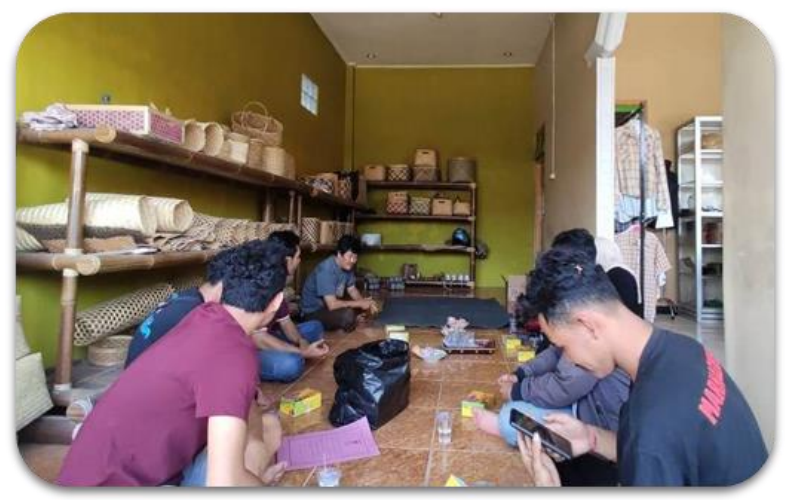

Gambar 7. Proses Pengarahan Kepada Mitra Tentang Kinerja Mesin dan Bentuk Perawatan Rutin

Proses berikutnya yaitu serah terima mesin kepada mitra yang kedepannya diharapkan mampu membantu proses pembuatan bahan 
anyaman agar lebih cepat dan efisien, menjadikan, serta hasil produksi yang akan meningkat dan mengurangi upah pekerja pengirat bambu sehingga mitra mendapat untung berlipat dari mesin ini. Berikut adalah proses serah terima mesin kepada mitra Sanggar Kerajinan Bambu Karya Nyata.

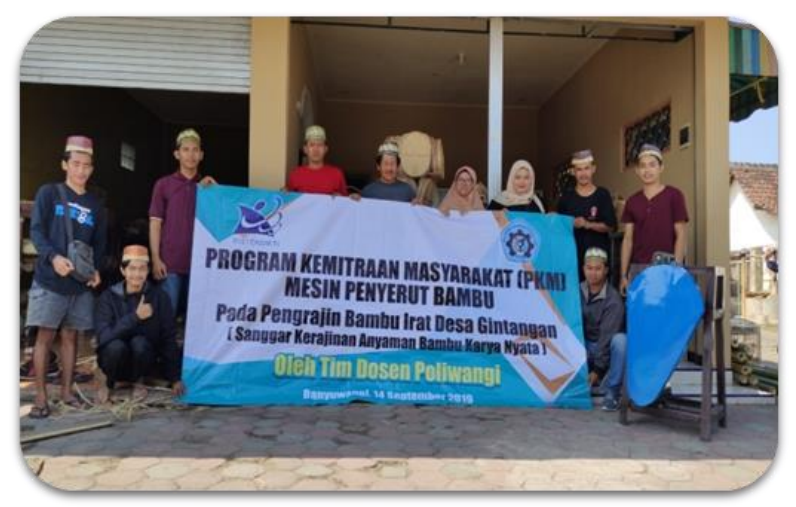

Gambar 8. Serah Terima Mesin Peyerut Bambu

\section{KESIMPULAN}

Permasalahan yang dialami mitra dalam proses penyerutan bambu ini diantaranya masih menggunakan pisau sebagai alat penyerut bambu, sehingga membahayakan pekerja serta mitra tidak dapat membeli mesin penyerut bambu irat yang ada dipasaran. Permasalahan tersebut diselesaikan melalui kegiatan pengabdian masyarakat yang dilaksanakan selama kurang lebih 4 bulan. Kegiatan pengabdian kepada masyarakat ini dilakukan dengan beberapa proses yaitu proses desain mesin yang efisien, proses pembuatan mesin, proses uji coba mesin dengan mitra, proses sosialisasi tentang penggunaan dan perwatan mesin kedepannya, proses uji coba mesin ditempat mitra, dan proses serah terima mesin kepada Sanggar Kerajinan Bambu Karya Nyata. Pada pengrajin bambu irat ini masih dibutuhkan beberapa mesin seperti mesin pembelah bambu, mesin penghalus serutan bambu. Sehingga kedepannya dapat dilanjutkan untuk melakukan pembuatan mesin yang sesuai dengan mitra.

\section{UCAPAN TERIMA KASIH}

Ucapan terima kasih yang sebesar-besarnya kami tujukan kepada Politeknik Negeri Banyuwangi karena telah membantu memberi dukungan pendanaan pada kegiatan hibah pengabdian kepada masyarakat melalui Pusat Penelitian dan Pengabdian Kepada Masyarakat, serta telah memfasilitasi proses pembuatan mesin dengan memberikan ijin peminjaman laboratorium pemesinan selama pengerjaan mesin Penyerut Bambu. Terima kasih kepada mitra Sanggar Kerajinan Bambu Karya Nyata yang telah bekerja sama dengan baik. 


\section{DAFTAR RUJUKAN}

Arsad, E. (2015). Teknologi Pengolahan Dan Manfaat Bambu. Jurnal Riset Industri

Hutan,

$7(1)$,

$45-52$.

https://doi.org/10.24111/jrihh.v7i1.856

Clark, L. G., London0, X., \& Ruiz-Sanchez, E. (2015). Bamboo Taxonomy and Habit. In Bamboo, Tropical Forestry (pp. 1-30). Springer International Publishing Switzerland. https://doi.org/10.1007/978-3-319-14133-6 1

Hadi, I. Al, Riastuti, R. D., \& Sepriyaningsih. (2017). Identifikasi Jenis Bambu (Bambusa Sp) di Desa Sidoharjo Kecamatan Tugumulyo Kabupaten Musi Rawas. http://mahasiswa.mipastkipllg.com/repository.

Ibrahim, G. A., Hamni, A., Welly, M., Andriyanto, R., \& Harjo, B. (2019). Pembuatan Dan Pengujian Mesin Penyerut Tusuk Sate Mekanik. Sakai Sambayan Jurnal Pengabdian Kepada Masyarakat, 3(1), 27-33. https://doi.org/10.23960/jss.v3i1.109

Jasni, Damayanti, R., \& Pari, R. (2017). Ketahanan Alami Jenis-Jenis Bambu yang Tumbuh di Indonesia Terhadap Rayap Tanah. Jurnal Penelitian Hasil

Hutan, 35(4),

289-301. https://doi.org/10.20886/jphh.2017.35.3.289-301

Kristanto, A., \& Arifin, Y. (2012). Perancangan Mesin Penyayat Bambu Secara Ergonomis. Jurnal Imliah Teknik Industri, 11(2), 113-124. https://doi.org/10.23917/jiti.v11i2.773

Malau, S. M., Muhidi, \& Azhar, I. (2009). Analisis Biomassa dan Cadangan Karbon Bambu Tali (Gigantochioa apus Kurz) di Hutan Rakyat Desa Sirpang Sigodang Kecamatan Panel Kabupaten Simalungun. Peronema Forestry Science Journal, 5(2), 1-13.

Muhtar, D. F., Sinyo, Y., \& Ahmad, H. (2017). Pemanfaatan tumbuhan bambu oleh masyarakat di kecamatan oba utara kota tidore kepulauan. Saintifik@ MIPA, 1(1), 37-44.https://doi.org/10.33387/sjk.v1i1.335

Riastuti, R. D., Febrianti, Y., \& Panjaitan, T. (2019). Eksplorasi Jenis Bambu di Kecamatan Rawas Ulu Kabupaten Muratara. BIOEDUSAINS: Jurnal Pendidikan Biologi Dan Sains, 2(1), 13-25. https://doi.org/10.31539/bioedusains.v2i1.719

Rofii, F., Hunaini, F., \& Tjahjono, N. (2018). Pembuatan Alat Pembelah Kayu dan Penyerut Bambu Pada Kelompok Usaha Pengrajin Sangkar Burung di Desa Toyomarto Kecamatan Singosari Kabupaten Malang. Jurnal Pengabdian Kepada Masyarakat, 24(2), 637-643. https://doi.org/10.24114/jpkm.v24i2.10130

Sary, N., Fahrizal, \& Yani, A. (2018). Jenis Bambu Di Hutan Tembawang Desa Suka Maju Kecamatan Sungai Betung Kabupaten Bengkayang. Jurnal Hutan Lestari, 6(3), 637-646. https://doi.org/10.26418/jhl.v6i3.27075

Sumpena, \& Jemadi. (2017). Teknologi Tepat Guna Mesin Irat Bambu Untuk Meningkatkan Produksi bagi Pengrajin Bambu Gedek Di Desa Karanganom, Kec. Klaten Utara, Kab. Klaten, Prop. Jawa Tengah. Jurnal Politama, $X V I(2)$, $61-65$. http://jurnal.politama.ac.id/index.php/jp/article/view/39 
Suryanto, Sarana, Suwarto, E., \& Suharto. (2015). Rancang Bangun Mesin Irat Dan Slicer Bambu Untuk Produksi Irat Bambu Sebagai Bahan Baku Kerajinan Kualitas Ekspor. Sentrinov (Seminar Nasional Terapan Riset Inovatif), 1(1), 225-235. http://proceeding.sentrinov.org/index.php/sentrinov/article/view/29

Triplett, J. K., Oltrogge, K. A., \& Clark, L. G. (2010). Phylogenetic relationships and natural hybridization among the north american woody bamboos (Poaceae: Bambusoideae: Arundinaria). American Journal of Botany, 97(3), 471-492. https://doi.org/10.3732/ajb.0900244

Winarno, J., \& Rusdiyantoro. (2016). Rancang Bangun Mesin Irat Bambu Untuk Pembuatan Jeruji Sangkar Burung dan Tusuk Sate. WAKTU Jurnal Teknik UNIPA, 14(1), 35-45. http://jurnal.unipasby.ac.id/index.php/waktu/article/view/06 